\title{
Effect of AZO Substrates on Self-Seeded Electrochemical Growth of Vertically Aligned ZnO Nanorod Arrays and Their Optical Properties
}

\author{
A. Peić, ${ }^{1}$ T. Dimopoulos, ${ }^{1}$ R. Resel, ${ }^{2}$ S. Abermann, ${ }^{3}$ M. Postl, ${ }^{4}$ \\ E. J. W. List, ${ }^{2,4}$ and H. Brückl ${ }^{1}$ \\ ${ }^{1}$ Health \& Environment Department, AIT Austrian Institute of Technology GmbH, Nano Systems, \\ Donau-City Straße 1, 1220 Vienna, Austria \\ ${ }^{2}$ Institute of Solid State Physics, Graz University of Technology, Petersgasse 16, 8010 Graz, Austria \\ ${ }^{3}$ Energy Department, AIT Austrian Institute of Technology GmbH, Giefinggasse 2, 1210 Vienna, Austria \\ ${ }^{4}$ NanoTecCenter Weiz Forschungsgesellschaft mbH, Franz-Pichler-Straße 32, 8160 Weiz, Austria \\ Correspondence should be addressed to A. Peić, antun.peic@gmail.com and T. Dimopoulos, theodoros.dimopoulos@ait.ac.at
}

Received 13 June 2012; Accepted 10 August 2012

Academic Editor: Xuedong Bai

Copyright (๑) 2012 A. Peić et al. This is an open access article distributed under the Creative Commons Attribution License, which permits unrestricted use, distribution, and reproduction in any medium, provided the original work is properly cited.

We present a single step and an electrochemical synthesis of vertically aligned $\mathrm{ZnO}$ nanorod (NR) arrays, directly on transparent aluminium-doped zinc oxide (AZO) electrodes. The NRs grow from mild, aqueous-based solution at low temperature, with no need for catalysts or additional seed layer. The use of textured AZO as substrate allows for highly effective growth of hexagonally faceted, single-crystalline $\mathrm{ZnO}$ NRs along the wurtzite $c$-axis. The matching of the crystal lattices initiates a self-seeding route, thus the inherent growth habit of the AZO crystallites advances the vertical growth and alignment of NRs. Moreover, the thicknessdependant grain size of the AZO layer provides a valuable feature for tuning the diameter of $\mathrm{ZnO}$ NRs grown atop. In the absence of any seed mediator, the interfacial quality is expected to improve significantly. This should enhance the thermal and electrical transport throughout the whole nanostructured transparent electrode. The NR growth was investigated under systematic manipulation of the synthesis variables in order to optimize growth conditions for highly aligned, single-crystalline NRs with a large aspect ratio and a good optical quality. The structure and optical property of the AZO/ZnO NR ensembles were characterized by atomic force microscopy, scanning electron microscopy, X-ray diffraction, photoluminescence, and ultravioletvisible transmission spectroscopy.

\section{Introduction}

With the intention of advancing the performance of new functional materials, sophisticated control over the morphology and the properties of inorganic (semiconductor) nanostructures remains a long-standing goal in the development of bottom-up device fabrication processes. Further development into geometric considerations is particularly desirable for the exploitation of the dimensionality of nanomaterials in connection with high surface area materials, functional nanoscale devices, electronics, biomaterials, and energy production. Creating large, well-aligned arrays of tailored 1D nanostructures on transparent electrodes provide a promising basis for a wide range of those targeted areas of application. Among many semiconductor nanomaterials, several favourable intrinsic properties have brought $\mathrm{ZnO}$ into focus for the use as functional nanostructured devices due to several potential benefits over traditional wafer-based components, such as, for example, good transparency, high electron mobility, wide bandgap $(3.36 \mathrm{eV})$, strong roomtemperature luminescence, large excitonic binding energy $(60 \mathrm{meV})$ at room temperature [1], piezoelectricity, high mechanical robustness, and excellent thermal and chemical stability [2]. $\mathrm{ZnO}$ is an earth abundant, thus, cheap native n-type semiconductor (due to oxygen vacancies) with lowtoxicity and good stability. By doping $\mathrm{ZnO}$, for example, 
with gallium (Ga), indium (In), and aluminium ( $\mathrm{Al}$ ), its conductivity may even be increased by orders of magnitude, thus offering an attractive and cheap, furthermore, nontoxic and rare metal-free alternative to the costly ITO [3-7].

Those properties are highly appreciated in emerging applications for transparent electrodes in liquid crystal displays [8], thin-film transistors [9], blue light emitting diodes [10], organic light emitting diodes [11, 12], and further in the fields of optoelectronics [13], sensing [14, 15], and piezoelectrics $[16,17]$, as well as for photovoltaic cells [18].

Especially after the $\mathrm{ZnO}$ nanowire dye-sensitized solar cell was reported [18], research on nanostructured $\mathrm{ZnO}$ based transparent electrodes was accelerated. Besides the low production costs for nanostructured $\mathrm{ZnO}$-based transparent electrodes, interest is mainly driven by its intrinsic easy processability, with the consequence of a wide range of diverse production methods made available already. However, it is crucial to have a synthesis method at hand, which allows for the systematic variation of process parameters, in order to control the interfacial nanostructure formation to a high extent. In the past, mostly high-temperature techniques such as chemical vapour deposition (CVD) and thermal evaporation have been in use to produce aligned high-aspect ratio $\mathrm{ZnO}$ nanostructures, for example, nanorod $(\mathrm{NR})$ /nanowire (NW) arrays. These processes are highly energy consuming and require expensive infrastructure, which made it necessary to search for simple low-cost alternatives with the potential for upscaling to fit industrial process flows with generally accessible techniques.

In respect thereof, we focus on the utilization of electrochemical deposition (ECD) methods which are attractive not only for their mild aqueous- based solution processing, the low synthesis temperature, and facile manipulation possibilities, but also for the potential of easy upscaling. Since the first demonstration of ECD for $\mathrm{ZnO}$ film deposition in $1996[19,20]$, it remains a widely used technique for the deposition of oxides as bulky or thin films and nanostructures [21]. The majority of reported protocols on ECD of $\mathrm{ZnO}$ nanorod arrays (NRAs), however, still rely on seeded growth on $\mathrm{ZnO}$ nanoparticles or thin films that are precoated on the substrate [22-26]. Consequently, a multistep process is necessary to provide the additional nucleation layer, which is not only tedious, but also the reproducibility of this step still remains challenging. Therefore, it is still crucially expected to achieve controllable large-scale growth of wellaligned $\mathrm{ZnO}$ nanostructures on transparent oxide electrode (TOE) substrates with a one-step synthetic approach, while maintaining the low-cost aspect.

Herein, we introduce an inexpensive and simple preparation of uniformly distributed and well-aligned vertical $\mathrm{ZnO}$ NRAs on conductive AZO electrodes, whereas no catalyst or seeding step is required for the initiation of controlled growth. This approach is based on a one-step electrochemical processing of consistently nontoxic and abundant materials in aqueous solution at low temperature $\left(\leq 85^{\circ} \mathrm{C}\right)$ and allows for large-scale processing at low cost, moreover it is favourable to the integration and in situ fabrication of complex and polymer-supported devices.
Recently, we demonstrated that growth of $\mathrm{ZnO}$ nanostructures by ECD is strongly related to the crystallinity and topology of the underlying TOE material [27]. In this work we study the application of AZO thin films as TOE for improved growth quality of vertically aligned singlecrystalline $\mathrm{ZnO}$ nanostructures atop. Instead of a seeding layer, in this approach we take advantage of the epitaxial relationship of the $\mathrm{ZnO}$ with individual grains of the highly $c$-axis-oriented AZO texture, thus avoiding any pretreatment step of the TOE surface. In the absence of any catalyst, surfactant, or seed mediator during the deposition, it is expected to significantly improve the interfacial quality as well. This, again, may enhance the thermal and electrical transport throughout the whole device.

We study ZnO NR growth on AZO substrates of various layer thicknesses ranging from 50 to $500 \mathrm{~nm}$. Investigation of the growth mechanism during ECD was carried out under systematic manipulation of the synthesis variables such as reactant concentration and temperature, in order to optimize growth condition for highly aligned large aspect ratio NR with good crystal and optical quality.

\section{Experimental Details}

2.1. Preparation of $A Z O$ Layer. AZO thin film TOEs with high transmittance of above $90 \%$ in the visible region and low resistivity of $2.1 \times 10^{-3} \Omega \mathrm{cm}$ were deposited by $\mathrm{DC}$ magnetron sputtering (Leybold Univex 450 C) in pure $\mathrm{Ar}$ atmosphere, from a 4 -in ceramic AZO target, corresponding to a $\mathrm{ZnO}$ target with $2 \mathrm{wt} . \% \mathrm{Al}_{2} \mathrm{O}_{3}$. Precut soda-lime glass slides (Menzel) with a refractive index of $n_{s}=1.53$ at $546 \mathrm{~nm}$ were used as substrates. Prior to use, the glass slides were subject to a standardized sequence of thorough cleaning steps by ultrasonication in acetone, iso-propanol, piranha solution, (3: 1 conc. sulphuric acid to $30 \%$ hydrogen peroxide solution), and finally in base piranha solution, (3:1 mixture of ammonium hydroxide $\left(\mathrm{NH}_{4} \mathrm{OH}\right)$ with hydrogen peroxide) for $10 \mathrm{~min}$ each. The glass substrates were watercooled during the sputter deposition and kept at $25^{\circ} \mathrm{C}$. The target-substrate distance was $10 \mathrm{~cm}$. The base pressure was in the range of $7 \times 10^{-6}-1 \times 10^{-5} \mathrm{~Pa}$. AZO was sputtered at a power of $160 \mathrm{~W}$ and $0.1 \mathrm{~Pa}$ Ar pressure, resulting in a deposition rate of $0.78 \mathrm{~nm} / \mathrm{sec}$. The deposition rate was accurately extracted from step-height measurements using an atomic force microscope (AFM) (Molecular Imaging, PicoPlus). In the following, the thickness of the films in nanometres is denoted with a subscript. For example, $\mathrm{AZO}_{250}$ stands for a $250 \mathrm{~nm}$ thick AZO film.

2.2. Aqueous Solution Growth of $\mathrm{ZnO}$ Nanorods. All chemicals used in this study were analytical grade and were used in the received form without further purification. The water used throughout this work was reagent-grade purified and deionized Milli-Q water $(18.2 \mathrm{M} \Omega \mathrm{cm})$.

Aqueous solutions of zinc nitrate hexahydrate $\left(\mathrm{Zn}\left(\mathrm{NO}_{3}\right)_{2} \cdot 6 \mathrm{H}_{2} \mathrm{O}\right.$, purum p.a. $\geq 99.0 \%$, Sigma-Aldrich) and hexamine $\left(\mathrm{C}_{6} \mathrm{H}_{12} \mathrm{~N}_{4}, \mathrm{HMT}\right.$, puriss. p.a. $\geq 99.5 \%$, SigmaAldrich), with equimolar concentration of $10^{-4} \mathrm{~mol} / \mathrm{L}$, were 
used for the deposition of $\mathrm{ZnO}$ NRAs. The reaction solution volume was about $200 \mathrm{~mL}$ in order to make a sufficient amount of precursor available. The aqueous solution was heated under permanent stirring at the reaction temperature for $1 \mathrm{~h}$ prior to immersion of a piece of AZO covered glass substrate (cathode) which was placed vertically in the reservoir. The chosen temperature was kept constant but was varied for individual experiments between $70^{\circ} \mathrm{C}$ and $85^{\circ} \mathrm{C}$ for upto $12 \mathrm{~h}$ on a regular laboratory hotplate. A wound platinum wire with a diameter of $0.5 \mathrm{~mm}$ was used as the counter electrode. A negative dc potential of $-1.0 \mathrm{~V}$ relative to an $\mathrm{Ag} / \mathrm{AgCl} / \mathrm{Cl}^{-}$reference electrode was applied to the TOE. At the end of the growth period, the sample was immediately removed from the solution and thoroughly rinsed in flowing deionized water to eliminate residual salts and unreacted products from the surface. The samples were dried under a moderate air flux at $70^{\circ} \mathrm{C}$.

2.3. Characterization Methods. The surface morphology of all AZO films was characterized by AFM imaging, operated in tapping mode. Scanning electron microscopy (SEM) (Zeiss SUPRA 40 microscope) was employed to observe the shape and cross-sections of ZnO NRAs and AZO films. Xray diffraction (XRD) was performed with a SIEMENS D501 diffractometer in Bragg-Brentano geometry. A sealed copper tube was used in combination with a graphite monochromator at the secondary side. The diffraction peaks were assigned to known crystallographic phases using the database Powder Diffraction File (PDF 2) from the International Centre for Diffraction Data (ICDD). Photoluminescence (PL) measurements were conducted on a Shimadzu RF5301PC spectrofluorophotometer at room temperature in air and the results were corrected with corresponding curves of the instrument. The optical transmission characteristics of the films and structures at normal light incidence were probed using an ultraviolet-visible (UV-VIS) spectrophotometer (Thermo Electron Corporation, Nicolet Evolution $100)$.

\section{Results and Discussion}

3.1. Characterization of AZO Substrates. Before the deposition of $\mathrm{ZnO}$ NRAs on AZO-coated glass substrates, the morphology of the TOE layer was characterized. Figure 1(a) shows a representative tapping mode AFM image of the $\mathrm{AZO}_{250}$ surface, from which the root mean square roughness (RMS $<3 \mathrm{~nm}$ ) was extracted, as well as the average grain size $(\mathrm{GS}=48 \mathrm{~nm})$. For the latter, the $2 \mathrm{D}$ autocorrelation function (ACF) of each topographic image was firstly calculated and then the profile of the central ACF peak was extracted (using the scanning probe microscopy data analysis software Gwyddion). The GS value corresponds to the full width at half maximum of the ACF peak. The GS, as well as the RMS roughness, increases almost linearly with the AZO film thickness for $d \leq 250 \mathrm{~nm}$, whereas for larger $d$, there is a tendency towards saturation [28]. The RMS roughness of the plain glass substrate is $0.16 \mathrm{~nm}$. The topographic AFM plot in Figure 1(a) indicates good preconditions for the use of $\mathrm{AZO}_{250}$ films without the need of an additional seeding process, since the topology already may offer facile nucleation sites.

Cross-section SEM images of the same $\mathrm{AZO}_{250}$ layer were obtained at the breaking edge after cleaving the samples, which inevitably led to the breaking of some grains. A representative cross-section SEM image of a close-packed $\mathrm{AZO}_{250}$ film on a glass slide is shown in Figure 1(b).The inherent columnar morphology of the film is clearly demonstrated. Near the glass/AZO interface many crystallites nucleate and start growing omnidirectional until the film thickness reaches $\sim 25 \mathrm{~nm}$. In later phases of the growth, some crystallites grow wider on the expense of others, resulting in the suppression of lateral growth; thus develop the characteristic V-shaped columns. It is commonly accepted that such a texture results from the competing growth between crystallites with different orientations. This, eventually, leads to the preservation of the grains with the faster growing direction-in this case the wurtzite hcp $c$-axis-perpendicular to the surface. The average sheet resistance of as-deposited AZO films was found to be inversely proportional to their thickness and independent of the grain size and not dominated by grain boundary scattering, as discussed in detail in a previous publication [28], yielding a constant resistivity of $2.1 \times 10^{-3} \Omega \mathrm{cm}$.

3.2. Self-Seeding Properties of AZO for $\mathrm{ZnO}$ Nanorod Growth. The chemical reactions concerning the applied ECD process for the formation of $\mathrm{ZnO}$ NRAs are generally known to be based on the generation of an excess of ionic species in solution, which are subsequently brought to precipitation by reduction of an oxygen precursor reactant in close proximity to the working electrode interface. The nucleation and growth mechanism of $\mathrm{ZnO}$ in aqueous solution have previously been investigated by numerous groups [29-31]. The general principle for the deposition of $\mathrm{ZnO}$ from an aqueous solution follows eventually as a result of the $\mathrm{pH}$ dependence of its solubility in aqueous solution [32] and can therefore be induced by increasing the concentration of hydroxide ions in solution. This, again, can be achieved by the cathodical reduction of a variety of oxygen precursors such as peroxide [33], molecular oxygen $[34,35]$, or nitrate $[36,37]$, with the following hydroxyl supply reaction schemes:

$$
\begin{gathered}
\mathrm{H}_{2} \mathrm{O}_{2}+2 \mathrm{e}^{-} \longrightarrow 2 \mathrm{OH}^{-} \\
0.5 \mathrm{O}_{2}+\mathrm{H}_{2} \mathrm{O}+2 \mathrm{e}^{-} \longrightarrow 2 \mathrm{OH}^{-} \\
\mathrm{NO}_{3}{ }^{-}+\mathrm{H}_{2} \mathrm{O}+2 \mathrm{e}^{-} \longrightarrow \mathrm{NO}_{2}^{-}+2 \mathrm{OH}^{-}
\end{gathered}
$$

In this study, we focus solely on the zinc nitrate $\left(\mathrm{Zn}\left(\mathrm{NO}_{3}\right)_{2}\right)$ route, as it conveniently delivers both, the hydroxide ions $\left(\mathrm{OH}^{-}\right)$as well as the zinc ions $\left(\mathrm{Zn}^{2+}\right)$ at once. The use of nitrate baths also avoids laborious gas handling equipment.

As a result of the progressing hydroxide production from the respective reduction of oxygen precursor (1)-(3) at the cathode surface, the local $\mathrm{pH}$ increases to over 10 and induces the preferred formation of intermediate zinc hydroxide species $[35,38]$. This alkaline environment is crucial for the formation of $\mathrm{ZnO}$ NRs because otherwise divalent metal ions do not hydrolyze under acidic conditions. 


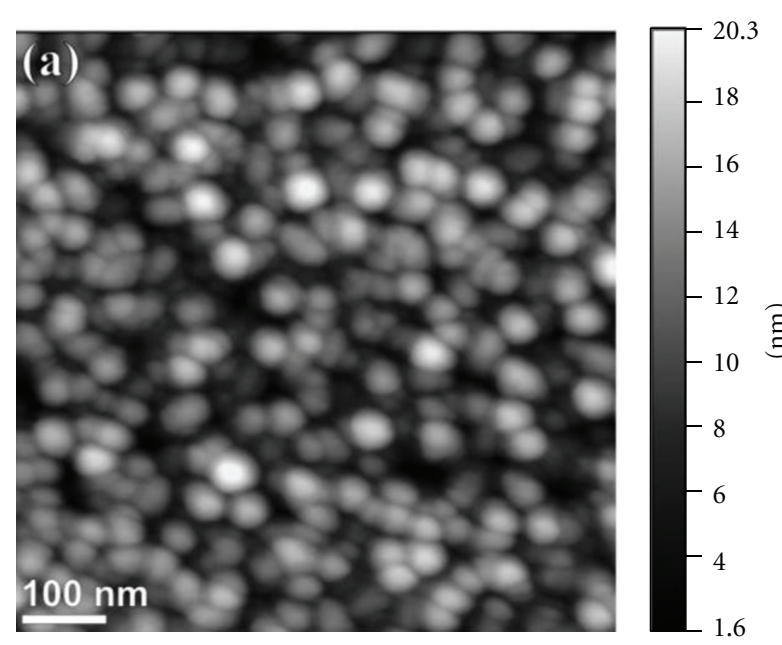

(a)

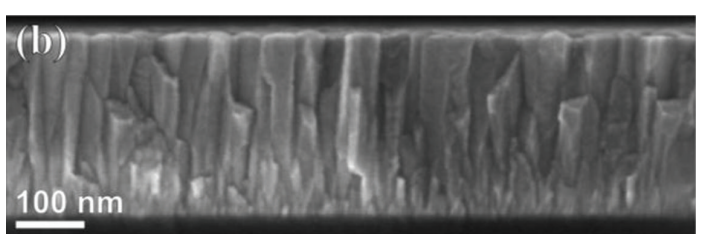

(b)

FIGURE 1: (a) AFM topography images and (b) cross-section SEM image of the AZO film with a thickness of $250 \mathrm{~nm}$, deposited on a sodalime glass slide.

In order to facilitate selective growth at the substrate surface, both its chemical and structural properties play a significant role. The interfacial tension between solution species and a crystal nucleation site depends on the degree of structural matching, the same crystal type having the best match and the lowest energy barrier [39].

Therefore, many ECD approaches depend on some kind of surface treatment of the electrode interface. The better this seed material then matches the material of the nanocrystals being grown, the more effectively it facilitates the electrochemically induced growth of $\mathrm{ZnO}$ NRs by controlling their morphology, texture, and even orientation. Due to the small lattice mismatch $(<1 \%)$ and large structural similarity (hexagon on hexagon epitaxy) in the case of AZO substrates ( $98 \mathrm{wt} \% \mathrm{ZnO}+2 \mathrm{wt} \% \mathrm{Al}_{2} \mathrm{O}_{3}$ ), plentiful low energy nucleation sites for $\mathrm{ZnO}$ crystallites are presented at the surface, hence the interfacial energy may be reduced to values close to zero and further seeding steps may be avoided.

In order to characterize the quality of AZO layers as TOEs with proposed self-seeding properties for ECD of ZnO NRAs, the deposition progress was monitored at frequent intervals during the first hour of deposition. In Figure 2, we present a sequence of SEM images, taken after $1 \mathrm{~min}$ (a), 5 min (b), $30 \mathrm{~min}$ (c), and $60 \mathrm{~min}$ (d) of $\mathrm{ZnO}$ deposition on $\mathrm{AZO}_{250}$. During these early stages of the ECD process, nucleation events are generated upon the electrochemical reduction of the $\mathrm{ZnO}$ growth species, leading to the formation of a solid precipitate of nanocrystalline $\mathrm{ZnO}$ atop the $\mathrm{AZO}_{250}$ film. Site-selective electrodeposition of $\mathrm{ZnO}$ nuclei at the $\mathrm{AZO}_{250}$ grain tips is intrinsically favoured over the nucleation events on intergrain boundaries, as shown in Figures 2(a) and 2(b). These initial nucleation events generate $\mathrm{ZnO}$ nanocrystals with the fastest growth rate being aligned to the wurtzite hcp $c$-axis of the columnar AZO grains, and therefore the $\mathrm{ZnO}$ nanocrystals soon begin anisotropically elongating along the matching direction to form one-dimensional structures whose diameter is dictated by the diameter of the $\mathrm{AZO}$ grain, as shown in Figures 2(c) and 2(d). Since each individual $\mathrm{ZnO}$ crystallite is growing on a separate grain of the $\mathrm{AZO}_{250}$ layer, thus following the columnar growth mode of the underlying $\mathrm{AZO}_{250}$ grains, this growth behaviour certainly may facilitate homogeneous coverage and electric continuity throughout the entire $\mathrm{AZO} / \mathrm{ZnO} \mathrm{NR}$ interface.

The bare $\mathrm{AZO}_{250}$ layer features a mean value of 475 grains $\mu \mathrm{m}^{-2}$. Following the sequence of SEM images in Figure 2 through the initial first hour of nucleation and growth, on $1 \mu \mathrm{m}^{2}$, we count 400 nuclei after $1 \mathrm{~min}$ (a), 325 nuclei after $5 \mathrm{~min}$ (b), 300 well-faceted crystallites are observed after $30 \mathrm{~min}(\mathrm{c})$, and after $60 \mathrm{~min}$ the substrate is homogeneously covered by $250 \mathrm{NR}$ (d). These results indicate that the $\mathrm{ZnO}$ NRAs grow in a competitive mode. The component of competition arises from the degree of misalignment and consequently restricted lateral space. Therefore, with progressing growth we observe a relative increase in perpendicular orientation of the NRs due to spatial hindrance and consequently the abortion of growth of the less perpendicular aligned NRs, which, again, provides an explanation for the decrease in NR density with increasing growth time.

Aside from the clearly visible progress in formation of aligned hexagonal crystallites, the SEM image in Figure 2(c) also reveals that the $\mathrm{ZnO}$ crystallites have grown to an average diameter of $50 \pm 5 \mathrm{~nm}$. After $60 \mathrm{~min}$, the continued ECD has formed $\mathrm{ZnO}$ NRs with highly anisotropic growth along their $c$-axis, with their final lateral dimension remaining constant at $50 \pm 5 \mathrm{~nm}$, as depicted in Figure 2(d). This close correspondence between the grain size of the $\mathrm{AZO}_{250}$ layer $(48 \pm 3 \mathrm{~nm})$ and the final $\mathrm{ZnO}$ NR diameter indicates a strong epitaxial relation between the substrate and the NRs, thus implying that growth is favourably following the columnar structure of the AZO substrate. Furthermore, this finding allows us to hypothesize that, by adjusting the AZO 


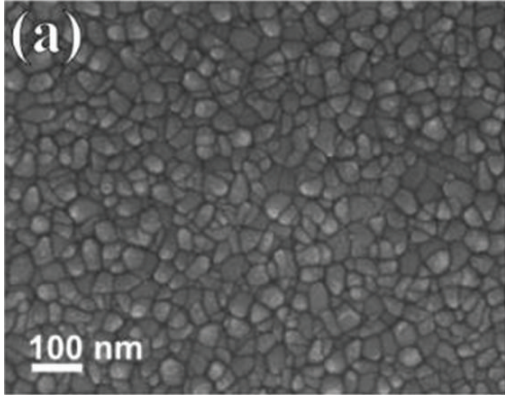

(a)

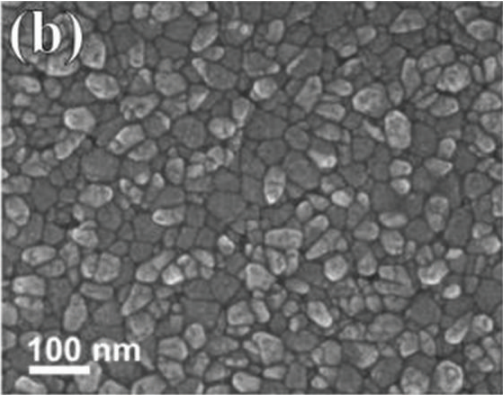

(b)

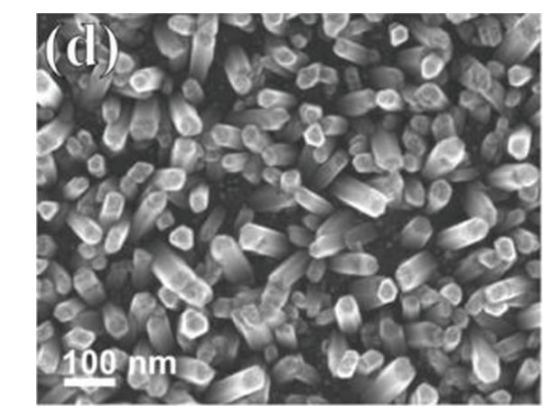

(d)

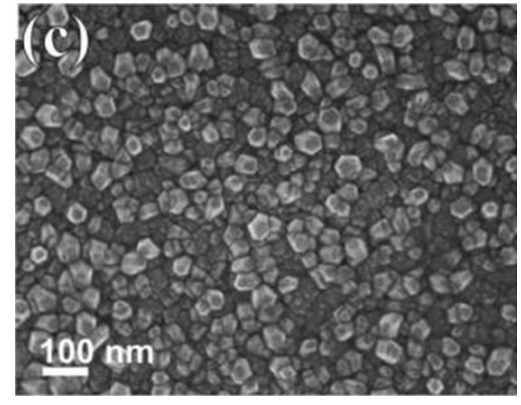

(c)

FIGURE 2: SEM images during initial $\mathrm{ZnO}$ nanorod growth on $\mathrm{AZO}_{250}$ at early stages of ECD. (a) $1 \mathrm{~min}$, (b) 5 min, (c) 30 min, and (d) 60 min $\left(T=75^{\circ} \mathrm{C}, E=-1.0 \mathrm{~V}\right)$.

layer thickness, which is correlated to its grain size, the NR diameter may be tuned accordingly.

3.2.1. Structural Analysis. X-ray diffraction on the bare AZO substrates shows clear features of the characteristic peak pattern of hexagonal $\mathrm{ZnO}$ (wurtzite type) as shown in Figure 3. The high intensity of the (0002) peak reveals highly textured crystallites within the film with the (0001) plane parallel to the substrate surface. The lattice constants of the crystallites, determined on the basis of the (0002) and the $(10 \overline{1} 3)$ peaks, have values of $a=3.269 \AA$ and $c=$ $5.256 \AA$. These values are close to the known lattice constant of hexagonal $\mathrm{ZnO}$ with $a=3.249 \AA$ and $c=5.206 \AA$. The difference is caused by $\mathrm{Al}$-atoms replacing $\mathrm{Zn}$-atoms substitutionally in the lattice accredited to the 2 wt. $\% \mathrm{Al}_{2} \mathrm{O}_{3}$ doping of $\mathrm{ZnO}$ in the $\mathrm{AZO}$ layer.

Figure 3 also gives the XRD pattern of the $\mathrm{ZnO}$ NRA on the $\mathrm{AZO}_{250}$ substrate after a total of $4 \mathrm{~h}$ of ECD (see Figures $10(\mathrm{a})$ and $10(\mathrm{~b})$ ). The peak pattern is comparable to the one of the uncoated $\mathrm{AZO}_{250}$ substrate but the intensity of the (0002) peak is considerably ( 30 times) higher. The other peaks of hexagonal $\mathrm{ZnO}$ are barely recognizable, but can be associated with $(10 \overline{1} 1),(10 \overline{1} 2)$, and (10 $\overline{1} 3)$ peaks of $\mathrm{ZnO}[40]$. It can be concluded that the $\mathrm{ZnO}$ NRAs consist of highly textured crystals forming a fibre texture with the (0001) fibre axis perpendicular to the substrate surface [20]. However, a slight change in the position of the (0002) peak is observed between $\mathrm{AZO}_{250}$ and the $\mathrm{ZnO}$ NRs. These results in a slightly different lattice constant for the $\mathrm{ZnO} N R$ crystals with $c=5.213 \AA$.

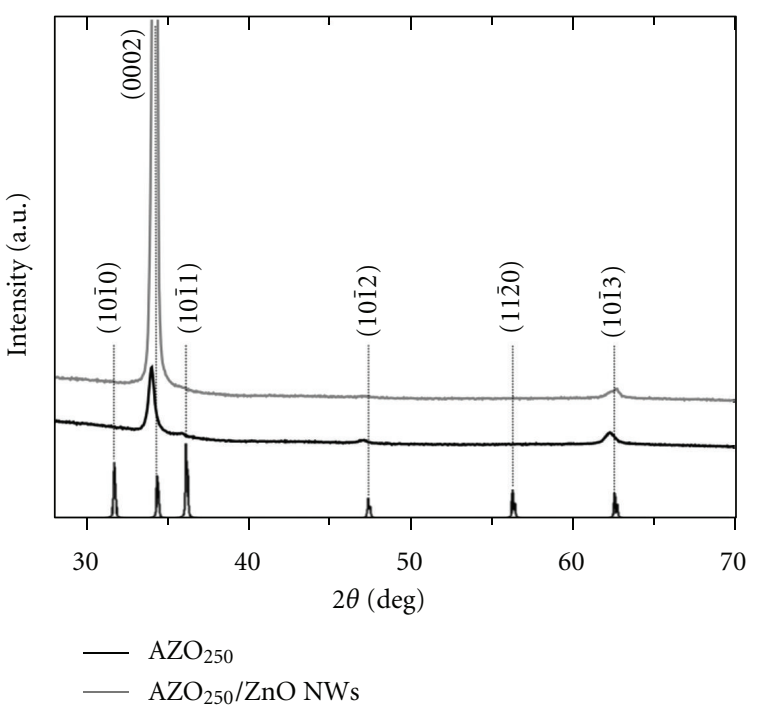

FIGURE 3: XRD specular scans of the $\mathrm{AZO}_{250}$ substrate and the $\mathrm{ZnO}$ NRA. The peaks at the base of the plot give the peak positions and relative intensities together with the indexation obtained from PDF36-1451 for hexagonal $\mathrm{ZnO}$ (Wurtzite).

We note here that the same dominant (0002) peak was observed in all XRD-investigated NRA samples, for various deposition temperatures and deposition times. The other peaks of the hexagonal $\mathrm{ZnO}$ are in all cases suppressed.

3.3. Effect of AZO Grain Size on ZnO NR Growth. Control over the nucleation location of $\mathrm{ZnO} \mathrm{NRs}$ at the beginning of 
the ECD is established by the columnar grains of the AZO substrate which serves as self-seeding back electrode. The density and size of these grains, however, are intrinsically controlled by the thickness of the TOE layer [28]. The effect of scaling grain size on the growth of $\mathrm{ZnO}$ NRAs by ECD is therefore investigated for various AZO layers with 50 to $500 \mathrm{~nm}$ thickness. Figure 4 shows SEM images of $\mathrm{ZnO}$ NRAs after $4 \mathrm{~h}$ deposition time at $85^{\circ} \mathrm{C}$ that were grown on $\mathrm{AZO}_{500}, \mathrm{AZO}_{250}, \mathrm{AZO}_{100}$, and $\mathrm{AZO}_{50}$, respectively. All investigated AZO films show homogeneous arrays of hexagonally shaped $\mathrm{ZnO}$ NRs with a continuous high degree of vertical alignment over several square centimetres. The variation in diameter and length of the NRs as well as the density of the NRAs is visible in SEM pictures in Figure 4. Plotting the mean diameter of the deposited $\mathrm{ZnO}$ NRs with the AZO grain size of the corresponding substrate against the underlying AZO film thickness clearly demonstrates the close spatial correlation, as shown in Figure 5. The remarkably close correlation of the average diameter of the NRs to the AZO grains goes hand in hand with a rapid decrease of the length of NRs from $2.5 \mu \mathrm{m}$ to $1.1 \mu \mathrm{m}$ with an increase in AZO layer thickness from $50 \mathrm{~nm}$ to $500 \mathrm{~nm}$. This indication of lattice matching with the substrate verifies the strong influence of the AZO surface morphology, more precisely the AZO grain size and density.

Dense NRs with aspect ratios of 17 and 25 are formed on $\mathrm{AZO}_{500}$ and on $\mathrm{AZO}_{250}$, respectively (Figures 4(a) and 4(b)). The NRs formed on $\mathrm{AZO}_{100}$ and especially on $\mathrm{AZO}_{50}$ (Figures 4(c) and 4(d)) show much larger aspect ratios of 50 and 83 , respectively.

As mentioned, the lateral dimension of the $\mathrm{ZnO}$ NRs is primarily dictated by the diameter of the AZO grains; however, we also observe significant changes in the density of the resulting NRAs according to the applied AZO film thickness. Considering the grain size and density of approximately 275 , 475,750 , and 2400 grains $/ \mu \mathrm{m}^{2}$ on respective substrates of $500,250,100$, and $50 \mathrm{~nm}$, we would expect a decreasing nucleation density with increasing thickness. Contrary to intuition, after $4 \mathrm{~h}$ of ECD we observe a decreasing density of NRs of $106,144,43$, and $23 \mathrm{NRs} / \mu \mathrm{m}^{2}$ for corresponding AZO thickness in decreasing order. The current passed after $4 \mathrm{~h}$ of ECD is nearly identical for all samples; thus it is implied that equal total amounts of $\mathrm{ZnO}$ material are deposited for all samples.

One possible reason for the strong effect of the AZO thickness on the self-seeding properties of the TOE on $\mathrm{ZnO} \mathrm{NR}$ growth, and according to density of the NRAs, can be rooted in the competition between nucleation of $\mathrm{ZnO}$ on AZO grains versus the axial growth of already formed crystallites. AZO films with lower sheet resistance facilitate electrochemically induced growth reaction, thus favour nucleation of $\mathrm{ZnO}$ at the TOE interface. Increased sheet resistance of the TOE, on the contrary, decreases the probability of nucleation, and hence rather favours the vertical growth of $\mathrm{ZnO} N R$ s along their $c$-axis.

Taking into account the thickness-dependent sheet resistance of the AZO films, thus plotting the average length of deposited $\mathrm{ZnO}$ NRs over the corresponding sheet resistance, we observe an almost linearly increasing correlation, as shown in Figure 6. The plot in Figure 6 also shows the rapid decrease of absolute surface area coverage from $45 \%$ and $37 \%$ for the $\mathrm{AZO}_{500}$ and $\mathrm{AZO}_{250}$, to only $6 \%$ and $2 \%$ for the $\mathrm{AZO}_{100}$ and $\mathrm{AZO}_{50}$, according to the increased sheet resistance of the TOEs. Electrochemically induced nucleation of $\mathrm{ZnO}$ growth species therefore appears to be enhanced on thicker AZO films, thus producing denser NRAs, compared to $\mathrm{ZnO}$ NRAs grown on thinner AZO films with higher sheet resistance.

These findings and the above stated assumptions were verified by a separate set of reference experiments. For this purpose $\mathrm{ZnO}$ NRAs were grown on symmetric $\mathrm{AZO} / \mathrm{Au} / \mathrm{AZO}$ trilayer TOEs (Figure 7) with superior electric properties [28]. With an optimized stack of $50 \mathrm{~nm} \mathrm{AZO/5} \mathrm{nm}$ $\mathrm{Au} / 50 \mathrm{~nm} \mathrm{AZO}$ a sheet resistance of approximately $30 \Omega$ is achieved while the grain size and morphology of the AZO top layer maintain the identical properties as the AZO monolayer with a thickness of $100 \mathrm{~nm}$. The presence of $\mathrm{Au}$ interlayer influences only moderately the grain structure of the AZO film. The RMS roughness and grain size of $\mathrm{AZO}_{50} / \mathrm{Au}_{5} / \mathrm{AZO}_{50}$ are 2.1 and $32 \mathrm{~nm}$, respectively, while the obtained values for the $\mathrm{AZO}_{100}$ single layer are 2.4 and $33.4 \mathrm{~nm}$. The nucleation density on these substrates is approximating full coverage with NRs during the first hour. Due to competitive growth, the density of the NRAs is gradually decreased with time to approximately $60 \%$ surface area coverage after $4 \mathrm{~h}$ of ECD. The NRs reach an average length of $1.5 \mu \mathrm{m}$ within this period of time.

3.4. Effect of Temperature on $\mathrm{ZnO}$ Nanorod Growth. Various thermochemical calculations regarding the electrochemically induced $\mathrm{ZnO} \mathrm{NR}$ growth from aqueous solutions have already elucidated that temperature has a variety of direct and indirect effects on the ECD process, mainly by a markedly high influence on the overall solubility of all precursor species. A closer look to the solution chemistry of the precursor species involved in the deposition process gives further insights. Diverse scenarios have been considered in the literature, commonly by predicting species repartition$\mathrm{pH}$ diagrams of the thermodynamically most stable $\mathrm{Zn}$ (II) species in solution during ECD, revealing generally accepted consequences, like the shift of their concentration maxima to lower $\mathrm{pH}$ with increasing temperature [41]. The required solution saturation for ECD techniques is set to be very close to the limit of $\mathrm{ZnO}$ solubility, therefore, already a slight change of the solubility conditions, due to thermodynamically induced changes, may result in a drastic impact on the nanostructure morphology.

Since optoelectronic properties strongly relate to the morphology of the nanostructures, it is crucial to better understand the effect of temperature on the ECD and the resulting morphology of $\mathrm{ZnO}$ NRAs. Temperature effects on the nucleation step and the formation of $\mathrm{ZnO}$ NRA were studied by ECD experiments, performed on various AZO substrate thicknesses at bath temperatures between $60^{\circ} \mathrm{C}$ and $85^{\circ} \mathrm{C}$. The corresponding top-view SEM images for NRAs grown on $\mathrm{AZO}_{250}$ are shown in Figure 8. Below $60^{\circ} \mathrm{C}$ synthesis of $\mathrm{ZnO}$ NRAs resulted only in partial coverage of 


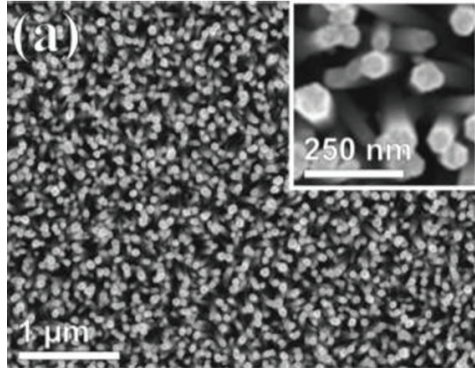

(a)

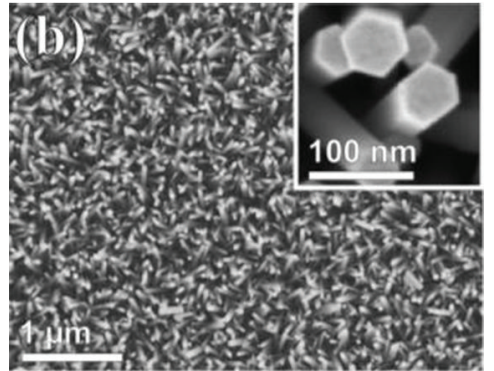

(b)

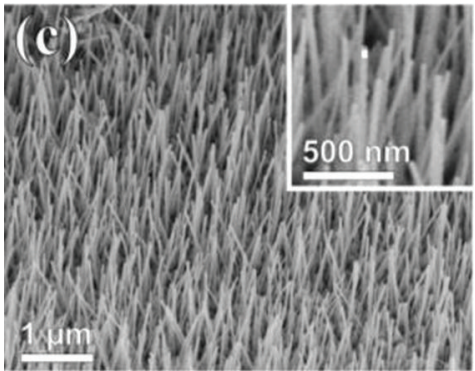

(c)

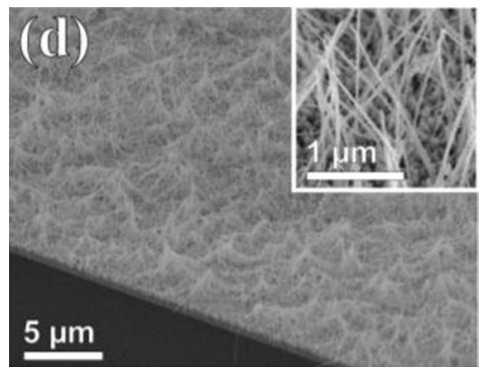

(d)

Figure 4: SEM images of electrochemically deposited $\mathrm{ZnO}$ NRAs $\left(-1.0 \mathrm{~V}, 4 \mathrm{~h}, 85^{\circ} \mathrm{C}\right)$ on $\mathrm{AZO}$ layers with varied thickness: $(\mathrm{a}) \mathrm{AZO}_{500}(d=$ $65 \mathrm{~nm}, l=1.1 \mu \mathrm{m}, \mathrm{AR}=17)$; (b) $\mathrm{AZO}_{250}(d=51 \mathrm{~nm}, l=1.3 \mu \mathrm{m}, \mathrm{AR}=25) ;(\mathrm{c}) \mathrm{AZO}_{100}\left(d=36 \mathrm{~nm}, l=1.8 \mu \mathrm{m}, \mathrm{AR}_{=}=50\right) ;(\mathrm{d}) \mathrm{AZO}$ 50 $(d=$ $30 \mathrm{~nm}, l=2.5 \mu \mathrm{m}, \mathrm{AR}=83$ ).

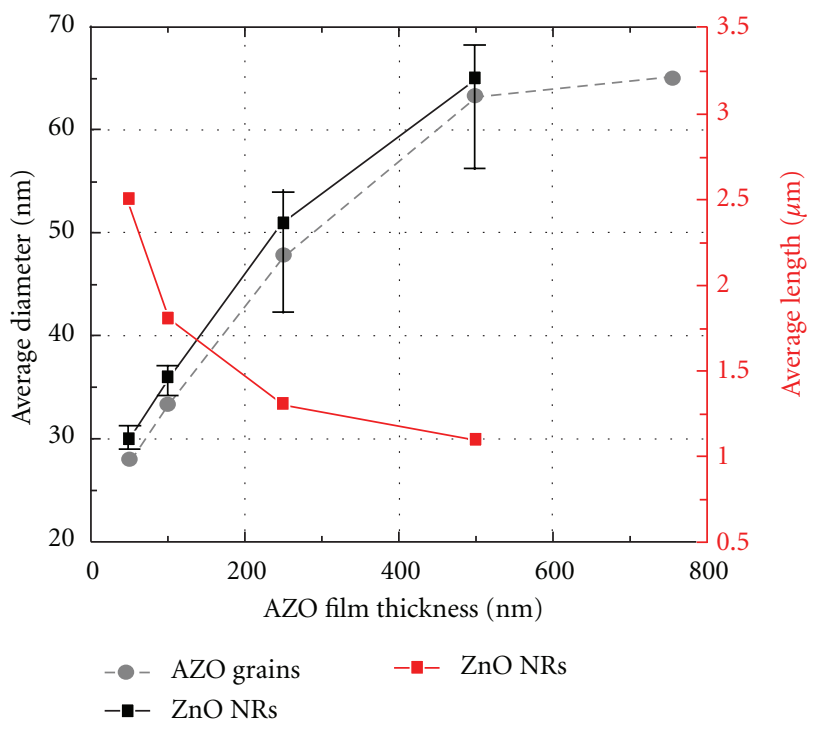

FIGURE 5: Plot showing the average diameter of AZO grains for AZO layers for varied thicknesses (grey dashed) in correlation with the increasing average diameter (black solid) and decreasing length (red solid) of NRs grown atop $\left(-1.0 \mathrm{~V}, 4 \mathrm{~h}, 85^{\circ} \mathrm{C}\right)$.

the substrate. This may be ascribed to decelerated reaction kinetics and hence poor nucleation in consequence of inefficient dehydration of the intermediate $\mathrm{Zn}$ (II) growth species at such relatively low temperatures. The SEM images in Figure 8 confirm that at $60^{\circ} \mathrm{C}$ and above, well-aligned, dense, and vertically oriented arrays of hexagonal $\mathrm{ZnO}$ NRs

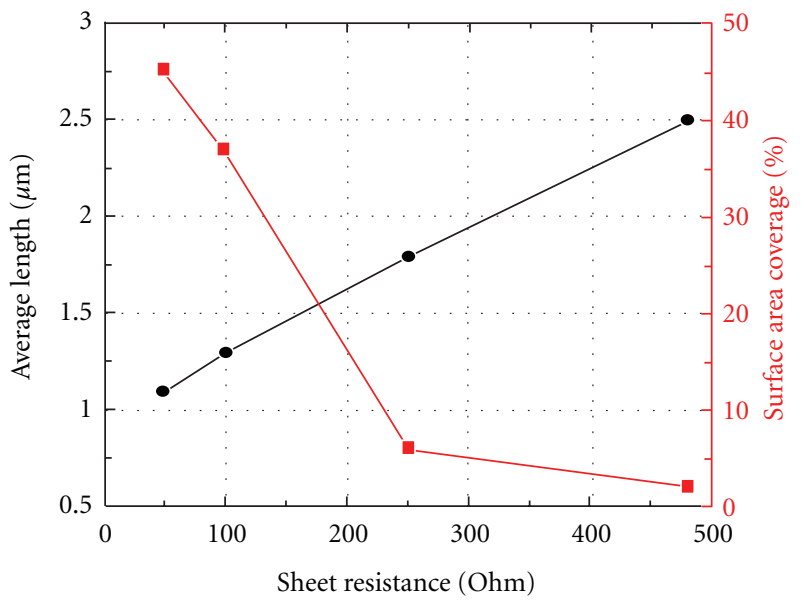

FIGURE 6: Plot showing the average length of $\mathrm{ZnO}$ NRs (black dots) and the percentage of surface area coverage (red squares) of different AZO substrate thicknesses as a function of their sheet resistance.

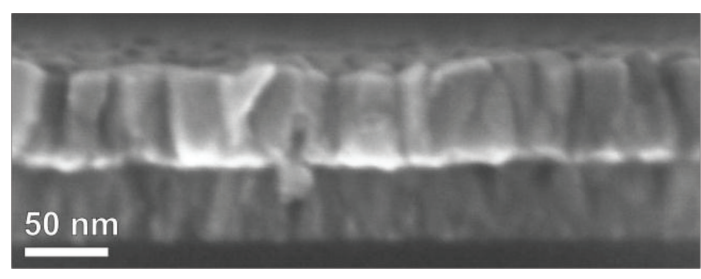

Figure 7: Cross-section SEM image of the $\mathrm{AZO}_{50} / \mathrm{Au}_{5} / \mathrm{AZO}_{50}$ trilayer film, deposited on a soda-lime glass slide. 
were grown with relatively uniform distribution. Top-view SEM images in Figure 8 show the resulting $\mathrm{ZnO}$ NRA from ECD at bath temperatures of (a) $60^{\circ} \mathrm{C}$, (b) $65^{\circ} \mathrm{C}$, (c) $70^{\circ} \mathrm{C}$, (d) $75^{\circ} \mathrm{C}$, (e) $80^{\circ} \mathrm{C}$, and (f) $85^{\circ} \mathrm{C}$.

The hexagonal cross-section of the NRs is clearly visible in the SEM close-up images (insets in Figures 8(a) to 8(f)), signifying the consistency of preferred growth along the (0001) direction throughout a broad range of temperature. From the structural point of view, it appears that the solution temperature does not have a major effect on the orientation of nanorods, but the impact is, a fortiori, affecting the AR of the NRs. Therefore, we notice that the $\mathrm{AR}$ of $\mathrm{ZnO} \mathrm{NRs}$ is increased from 4 to 25 with increasing temperature of the ECD bath from $60^{\circ} \mathrm{C}$ to $85^{\circ} \mathrm{C}$. The average diameter of the NRs decreases with increasing temperature from $106 \mathrm{~nm}$ at $60^{\circ} \mathrm{C}$ to $65 \mathrm{~nm}$ at $75^{\circ} \mathrm{C}$ until it reaches a minimum of $51 \mathrm{~nm}$ at $85^{\circ} \mathrm{C}$, as shown in Figures 8 (a) to $8(\mathrm{f})$, respectively. Likewise we observe that the length of the NRs was greatly affected by temperature changes, thus increasing with the temperature being raised within the tested range. Hence, after being subjected to the ECD process for a time period of $4 \mathrm{~h}$, the average $\mathrm{ZnO} N R$ lengths achieved were $0.4 \mu \mathrm{m}, 0.6 \mu \mathrm{m}, 1.1 \mu \mathrm{m}, 1.4 \mu \mathrm{m}, 1.3 \mu \mathrm{m}$, and $1.3 \mu \mathrm{m}$ for the respective temperatures in ascending succession. The significantly larger aspect ratios at increased temperatures may be explained by the overstepping of the critical temperature threshold for efficient NR growth. These results clearly imply the significance of the solution temperature as an essential parameter for controlling the $\mathrm{ZnO}$ nanostructure morphology, and thus, the resulting properties of those.

The graph in Figure 9 illustrates the effect of deposition temperature on the NR morphology. The continuous trend of decreasing NR diameter with increasing temperature is observed for all tested AZO film thicknesses, whereas the opposite trend is observed for the average length of the NRs. Interestingly, a significant maximum in vertical growth is repeatedly detected in the temperature range between $70^{\circ} \mathrm{C}$ and $80^{\circ} \mathrm{C}$. This kink in the average $\mathrm{ZnO}$ NR diameter curve indicates the optimum growth temperature after reaching a deposition temperature of $70^{\circ} \mathrm{C}$ or greater. According to the finding that at $75^{\circ} \mathrm{C}$, where the aspect ratio is superior to other deposition temperatures, this temperature was selected for further characterization.

3.5. Effect of Growth Time. For obtaining a better understanding of the formation mechanisms and the growth progression of $\mathrm{ZnO}$ NRAs on AZO TOEs, we carried out a series of time-dependent experiments. The reaction parameters for this study were chosen, according to the above discussed criteria for optimal growth with respect to our goal, which is the production of homogeneous high aspect ratio $\mathrm{ZnO}$ NRAs with accessible void space and large interfacial area to facilitate surface treatment and functionalization of the $\mathrm{ZnO}$ interfaces for, for example, photovoltaic (PV) application. The morphological evolution of $\mathrm{ZnO}$ NRAs is therefore traced during $12 \mathrm{~h}$ and the corresponding SEM images of the produced NRAs are shown in $4 \mathrm{~h}$ steps in Figure 10.

The SEM images show top views and the corresponding cross-sections of the NRAs, deposited from solutions containing $1 \mathrm{E}-4 \mathrm{~mol} / \mathrm{L} \mathrm{Zn}(\mathrm{II})$ precursor with equimolar addition of $\mathrm{HMT}$ at $75^{\circ} \mathrm{C}$. When the reaction is performed for the first $4 \mathrm{~h}$, vertically aligned $\mathrm{ZnO}$ NRAs are formed, with a diameter of $65 \mathrm{~nm}$ and a length of $1.4 \mu \mathrm{m}$, which correspond to $\mathrm{AR} \sim 22$ (Figures 10(a) and 10(b)). The crystal faces appear well developed and smooth with no visible structural defects. In preceding time experiments, we determined that the $\mathrm{ZnO} \mathrm{NR}$ surface begins to become rough as a result of long deposition times $(>6 \mathrm{~h})$, implying partial dissolution of the NRs [25]. The $\mathrm{ZnO}$ dissolution is ascribed to the equilibrium reaction with the depleting concentration of available precursor in solution. Therefore, in order to circumvent dissolution of deposited ZnO NRAs, we successively refreshed the deposition solution in $4 \mathrm{~h}$ cycles. The resulting NRA after two subsequent $4 \mathrm{~h}$ ECD cycles is shown in Figures $10(\mathrm{c})$ and $10(\mathrm{~d})$. Due to the refreshed solution, we observe $\mathrm{ZnO}$ NRs with smooth facets throughout the whole sample. The highly aligned NRAs exhibit diameters of $100 \mathrm{~nm}$ and a length of $2.9 \mu \mathrm{m}$, which correspond to $\mathrm{AR} \sim 29$. It is expected that the radial growth rate decreases with time, whereas the axial growth rate is continuously high. Because of the refreshed solution, we reintroduce the original concentration of the precursors at the beginning of each $4 \mathrm{~h}$ cycle, accordingly the nucleation potential is enhanced and we observe a slight increase of the radial growth rate at the beginning of each cycle, thus the average NR diameter after $8 \mathrm{~h}$ is slightly larger than the average NR diameter after $4 \mathrm{~h}$. This is in good agreement with the precursor concentration effect on the NR morphology as discussed above. As the experiment is prolonged to $12 \mathrm{~h}$, we obtain homogeneous arrays of highly aligned $\mathrm{ZnO}$ NRs with an average diameter of $150 \mathrm{~nm}$ and a length of $5.1 \mu \mathrm{m}$, which correspond to an $\mathrm{AR} \sim 34$. It is clearly indicated that not only the absolute length of the NRs is increasing with reaction time, but, moreover, it is demonstrated that the AR of the NRs continues to increases with deposition time.

From the sequence of top-view SEM images in Figure 10, it is also apparent that the density of NRs at the growth front is decreasing with deposition time, namely, from $60 \mathrm{NR} / \mu \mathrm{m}^{2}$ after $4 \mathrm{~h}$ to $55 \mathrm{NR} / \mu \mathrm{m}^{2}$ after $8 \mathrm{~h}$ and to finally $40 \mathrm{NR} / \mu \mathrm{m}^{2}$ after $12 \mathrm{~h}$. This decreasing density of $\mathrm{ZnO}$ NRs with increasing growth time can be explained by the competitive growth behaviour inherent to the axial growth of the NRs within the NRA. During the evolution of $\mathrm{ZnO}$ NRs, we observe homogeneous growth rates throughout the whole substrate. However, this assumption only holds for the axial growth along the $c$-axis of each individual NR. This process also features autoalignment of the NRs during the ECD process to a high-degree perpendicular to the substrate. Furthermore, since steady supply with growth units from the aqueous solution is required for continuous growth, the most perpendicular aligned NRs may be reached more easily by the growth units, and hence are accelerated in their growth rate. The SEM images in Figure 10 offer clear evidence for this competitive growth rate during the growth period of $12 \mathrm{~h}$. Taking into account the hexagonal geometry of the NRs, the length, and their density, we calculated an increase of the available surface area (compared to a flat film) by 60 times 

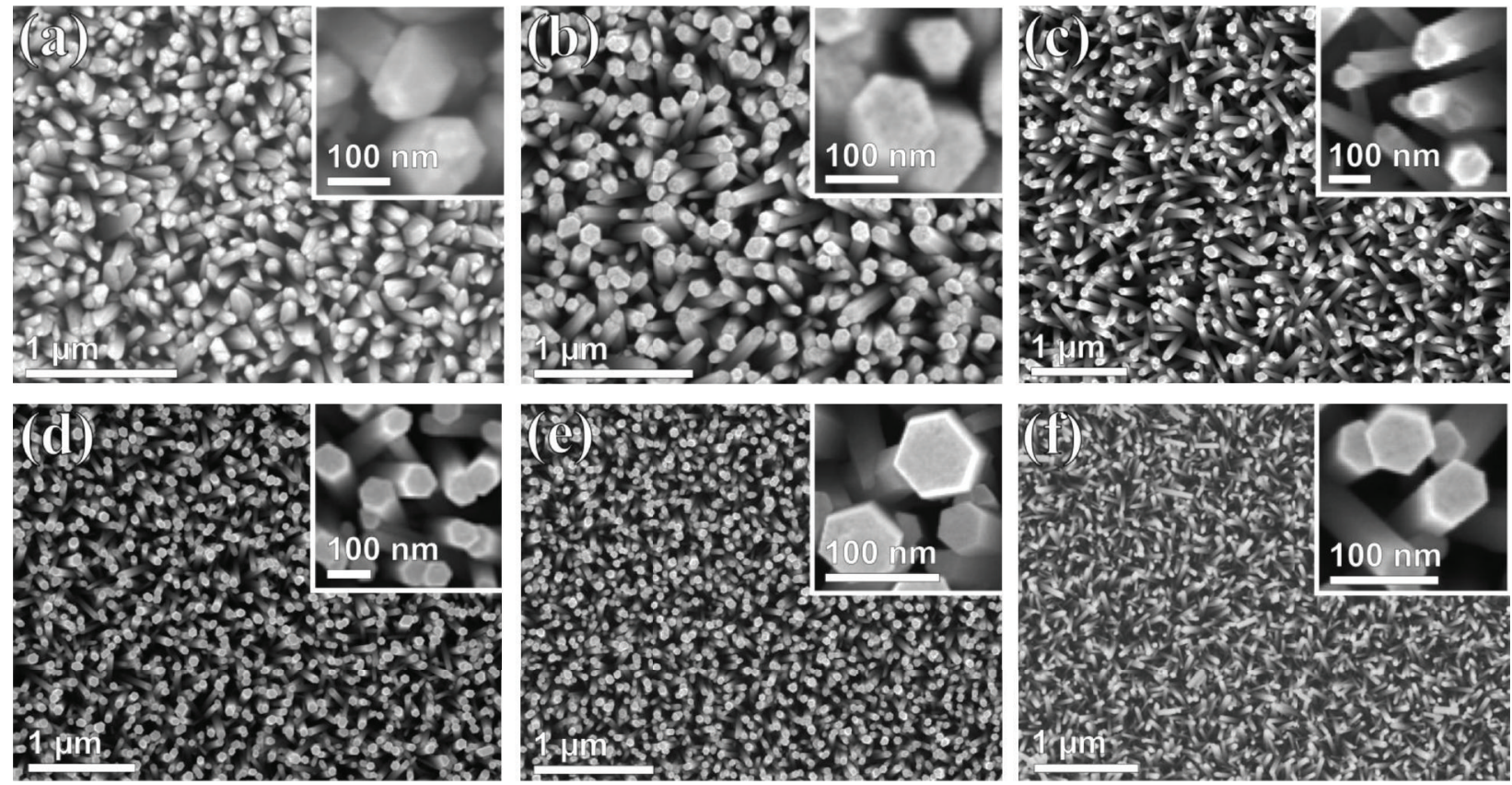

Figure 8: SEM images of electrochemically deposited $\mathrm{ZnO}$ NRAs $(E=-1.0 \mathrm{~V}, t=4 \mathrm{~h})$ on $\mathrm{AZO}_{250}$ substrates at a range of deposition temperatures: (a) $60^{\circ} \mathrm{C}$, (b) $65^{\circ} \mathrm{C}$, (c) $70^{\circ} \mathrm{C}$, (d) $75^{\circ} \mathrm{C}$, (e) $80^{\circ} \mathrm{C}$, and (f) $85^{\circ} \mathrm{C}$.

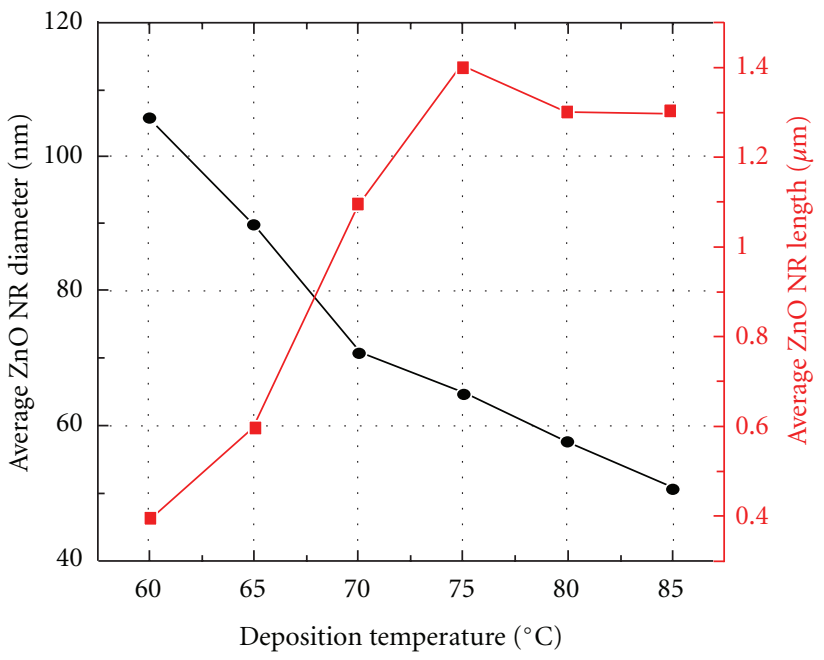

Figure 9: Plot showing the trends of the average $\mathrm{ZnO} \mathrm{NR}$ diameter (black dots) and length (red squares) over the deposition temperature atop $\mathrm{AZO}_{250}$ substrates.

for the NRA after $4 \mathrm{~h}, 140$ times after $8 \mathrm{~h}$, and 315 times after $12 \mathrm{~h}$.

Considering our aim, it is, on one hand, highly desirable to increase the available surface area to facilitate a maximum of interfacial area, but the consequences of the larger nanostructures, on the other hand, have to be carefully balanced to preserve optimal optical properties for the intended application as transparent component in, for example, new solar cell designs. Figure 11 shows the transmittance of only the $\mathrm{AZO}_{250}$ film on a soda-lime glass substrate, as a function of the wavelength, the typical thickness-related interference pattern for normal light incidence. The transmittance measurement of the $\mathrm{ZnO}$ NRA after $4 \mathrm{~h}$ (atop the glass/AZO ${ }_{250}$ ) (Figure 11) shows a decrease of about 20\% (compared to the soda-lime glass substrate) in the visible wavelength range from $350-570 \mathrm{~nm}$, whereas a slight increase is observed in the visible wavelength range from $570-800 \mathrm{~nm}$. All spectra are presented as recorded, thus including the fractions from the soda-lime glass. Therefore, the transmission spectrum of only the glass substrate is plotted separately for comparison. The three glass $/ \mathrm{AZO}_{250} / \mathrm{ZnO}$ NRA UV-Vis spectra correspond to the samples produced in the time experiment after $4 \mathrm{~h}, 8 \mathrm{~h}$, and $12 \mathrm{~h}$, respectively.

As expected, the UV-Vis transmission spectra show decreasing transmittance with increasing deposition time due to increasing NR dimensions. The spectra also show a typical excitation absorption band at $\sim 370 \mathrm{~nm}$ that is blue shifted with respect to the bulk absorption edge which appears at $400 \mathrm{~nm}$; this shift may be ascribed to the nanosize effect of the $\mathrm{ZnO}$ NRA [42]. Further, it is indicated that the smaller average diameter of $\mathrm{ZnO}$ NRs outperforms the $\mathrm{ZnO}$ NRAs with larger average diameter by significantly higher transmission, whereas, the greatest difference in transmission appears in the spectral region between $370 \mathrm{~nm}$ and $650 \mathrm{~nm}$. We infer from these results that $\mathrm{ZnO}$ NRAs with smaller average NR diameter are more favourable for TOE applications, thus can readily be applied as transparent nanostructured electrodes for, for example, PV application to increase the contact area between $\mathrm{ZnO}$ and the absorber, 

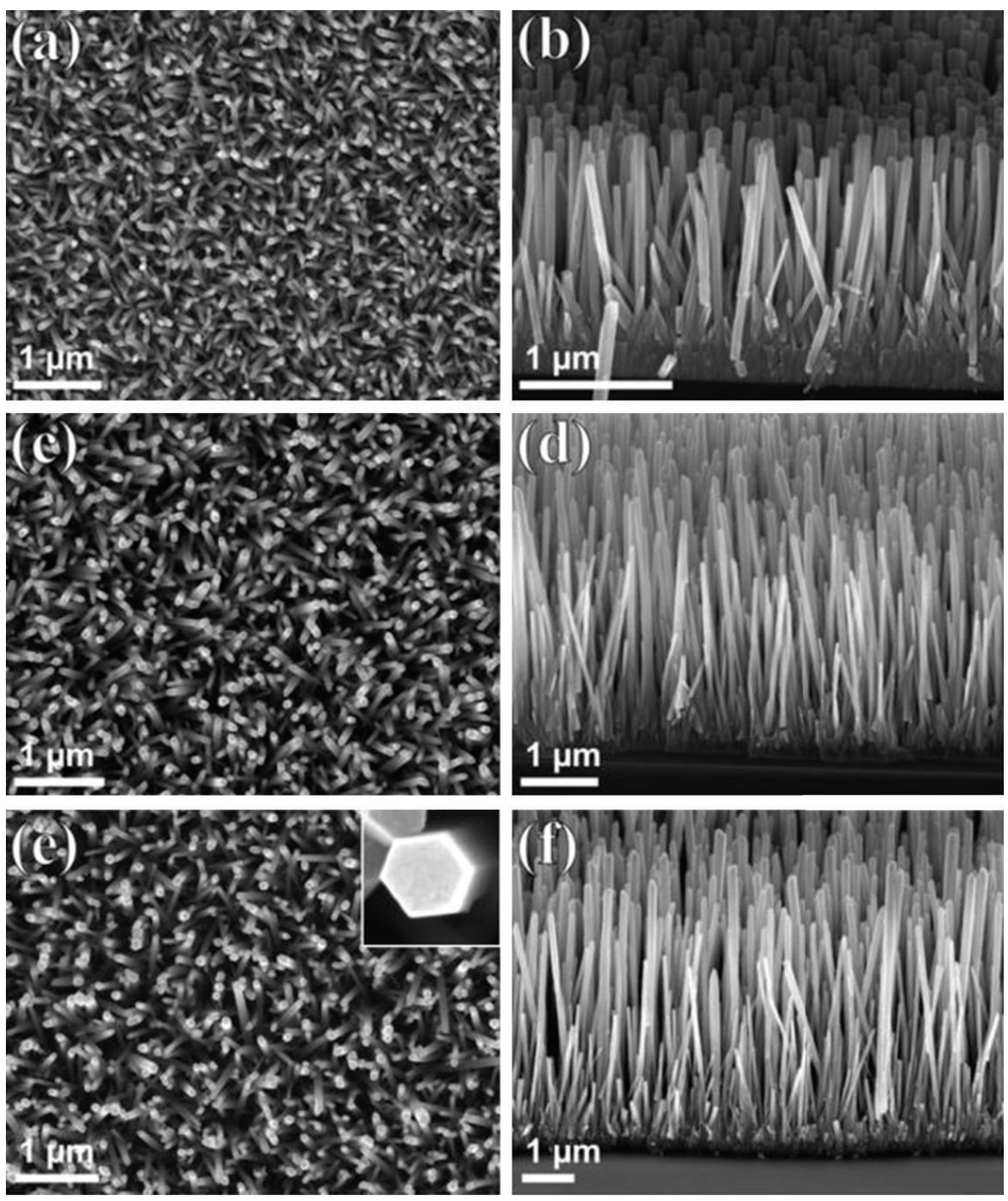

Figure 10: SEM images showing the evolution of electrochemically deposited $\mathrm{ZnO}$ NRAs on $\mathrm{AZO}_{250} / \mathrm{glass}$ at $75^{\circ} \mathrm{C}$ after $4 \mathrm{~h}(\mathrm{a}, \mathrm{b}), 8 \mathrm{~h}(\mathrm{c}, \mathrm{d})$, and $12 \mathrm{~h}(\mathrm{e}, \mathrm{f})$. Further details are given in the text.

resulting in possible enhancement of efficiency in new solar cells. The inset in Figure 11 shows a photograph of the corresponding $\mathrm{ZnO}$ NRAs on glass $/ \mathrm{AZO}_{250}$, with the scale bar in $\mathrm{cm}$.

\subsection{Effect of Deposition Temperature and Postdeposition} Temperature Treatment on the Photoluminescence of $\mathrm{ZnO}$ Nanorod Arrays. Photoluminescence (PL) spectra of NRAs were measured using a Xenon lamp (325 nm) as excitation source. Figure 12 shows typical room-temperature PL spectra of two glass/ $/ \mathrm{AZO}_{250} / \mathrm{ZnO}$ NRA samples after $4 \mathrm{~h}$ ECD at $70^{\circ} \mathrm{C}$ and $75^{\circ} \mathrm{C}$, as well as the bare glass $/ \mathrm{AZO}_{250}$ as reference for comparison. The PL of all as-prepared $\mathrm{ZnO}$ NRAs comprises one major emission band with a maximum at $\sim 3.2 \mathrm{eV}(\sim 390 \mathrm{~nm})$ in the ultraviolet (UV) region, which is attributed to the near-band-edge emission through excitonexciton collision processes [43]. This sharp and intense emission, which is associated with the good crystallinity and high chemical purity of the $\mathrm{ZnO} \mathrm{NRs}$, is in accordance with the expected optical band gap of $\mathrm{ZnO}$. A weak blue emission peak with much lower intensity, centred at $\sim 2.6 \mathrm{eV}$ $(\sim 470 \mathrm{~nm})$, is also observed in both spectra. It is reported that this $2.6 \mathrm{eV}$ emission peak-generally nominated as deep level emission (DLE) - presumably originates in the electron-hole recombination at a deep level in the band gap caused by intrinsic point defects and surface defects, for example, oxygen vacancies, zinc interstitials, and the incorporation of hydroxyl groups in the crystal lattice during the growth in solution $[44,45]$. The major difference between the $\mathrm{PL}$ emission characteristics, regarding the variation in deposition temperature of $\mathrm{ZnO}$ NRA samples, is manifested in the great discrepancy of the intensity of the belowband-gap DLE peak, centred at $\sim 2.0 \mathrm{eV}(\sim 600 \mathrm{~nm})$, which, however, is typical in $\mathrm{ZnO}$ prepared from aqueous solution and considered to be nonradiative recombination caused by oxygen vacancies in $\mathrm{ZnO}$ [46]. This DLE peak is commonly 


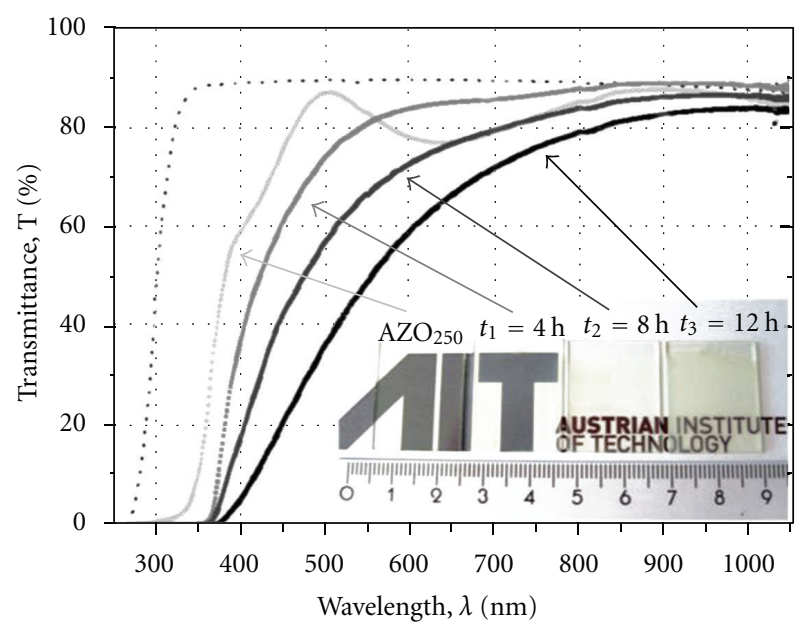

FIGURE 11: Optical transmittance measurements, showing the UVVis transmission spectra of $1 \mathrm{~mm}$ thick soda-lime glass (dotted), $250 \mathrm{~nm}$ sputter deposited AZO on soda-lime glass (solid, light grey), and electrodeposited $\mathrm{ZnO}$ nanorods on soda-lime glass/ $\mathrm{AZO}_{250}$ after $4 \mathrm{~h}, 8 \mathrm{~h}$, and $12 \mathrm{~h}$ (solid, from gray to black). The inset depicts a photograph of ZnO NRA samples on AZO-coated soda-lime glass substrates after each $4 \mathrm{~h}$ ECD cycle.

associated with surface electronic states at the NR surface [47] and atomic defects [48]. The much lower intensity of the DLE relative to the band-edge emission shows that the optical properties of NRAs are not dominated by surface defects but are intrinsic of bulk $\mathrm{ZnO}$. This is indicative of the high crystal quality of the electrochemically produced ZnO NRAs. Nevertheless, it also highlights the better optical quality of the NRA produced at higher temperature $\left(\geq 75^{\circ} \mathrm{C}\right)$. Accordingly, this demonstrates that increasing the ECD growth temperature to the optimal temperature at $75^{\circ} \mathrm{C}$ will improve the crystal quality of $\mathrm{ZnO}$ NRAs. Possible reasons for the significant sensitivity of the PL emission characteristics to the ECD synthesis temperature may be related to nucleation and growth kinetics through the activation of the reactants by the use of elevated temperature, hence the formation mechanism of oxygen vacancies. The use of elevated temperatures may also increase surface mobility and diffusion length of adsorbed building blocks, which, again, may improve the crystal quality. This clearly demonstrates that well-aligned $\mathrm{ZnO}$ NRAs with high crystal and optical quality can be synthesized directly on AZO substrates by the low-temperature ECD growth process.

In order to investigate to what extent further optical improvement can be achieved by postdeposition thermal treatment, the $\sim 5.1 \mu \mathrm{m}$ long NRAs $\left(12 \mathrm{~h} \mathrm{ECD}\right.$ at $\left.75^{\circ} \mathrm{C}\right)$ were subjected to an annealing step in air at $250^{\circ} \mathrm{C}$ for $2.5 \mathrm{~h}$. Figure 13 shows typical room-temperature PL spectra resulting from the NRAs before and after the heat treatment, respectively. The dominant UV emission peak remains unchanged at $\sim 3.2 \mathrm{eV}(\sim 390 \mathrm{~nm})$, together with the two rather weak visible emissions at $\sim 2.6 \mathrm{eV}(\sim 470 \mathrm{~nm})$ and $\sim 2.0 \mathrm{eV}(\sim 600 \mathrm{~nm})$. The UV to visible emission ratio, however, is reduced when comparing to the shorter NRAs

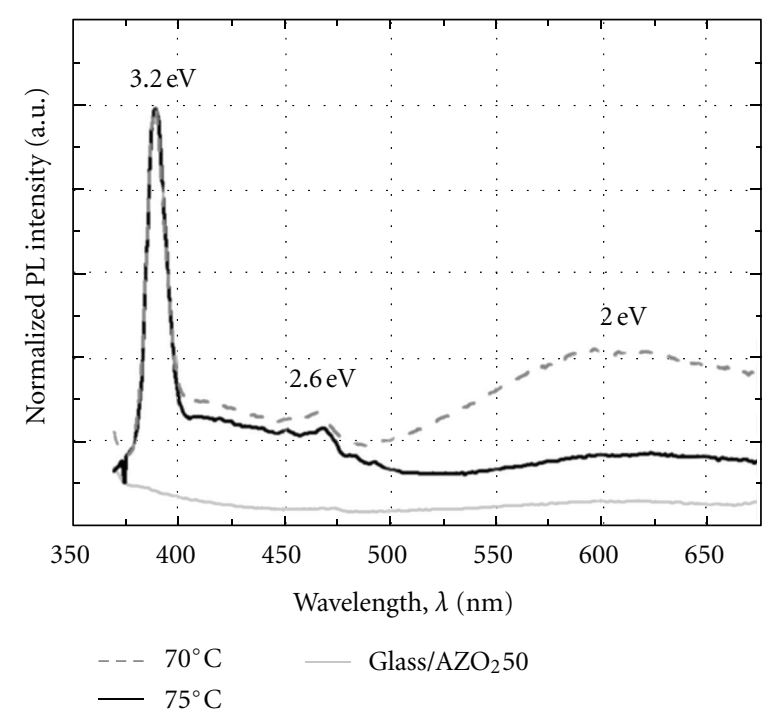

FIgURE 12: PL spectra of $\mathrm{ZnO}$ NRAs grown at $70^{\circ} \mathrm{C}$ (grey dashed) and $75^{\circ} \mathrm{C}$ (black solid) after a growth time of $4 \mathrm{~h}$. For comparison we include the soda-lime glass/ $\mathrm{AZO}_{250}$ (grey solid) reference. The PL spectra were recorded with an excitation wavelength of $325 \mathrm{~nm}$.

obtained after $4 \mathrm{~h}$, which is mainly caused by the increased emission at $\sim 470 \mathrm{~nm}$, rather than a decrease of the emission peak at $\sim 390 \mathrm{~nm}$. We may explain the relative increase in visible emission intensity, which is likely due to the formation of surface states and depletion layers near the NR surface, with the increased surface-to-volume ratios of the longer NRs. Close to the surface region, when electrons are excited to the conduction band, they are easily trapped by highdensity surface states and are relaxed via a nonradiative process, so that photon emission can occur only in the central region of the $\mathrm{ZnO}$ nanorods, deep from the surface. This plays an important role in the PL process. It is clear that the structural defects of $\mathrm{ZnO}$ NRAs are noticeably reduced after the thermal treatment. The marked overall quenching of the broad visible emission around after annealing is attributed to excess oxygen [49] and is consistent with the involvement of oxygen interstitials in the luminescence. For NRAs annealed at $250^{\circ} \mathrm{C}$, the weak blue emission is only slightly reduced. This persistence is attributed to only a slight increase in crystallinity of the film at this relatively low annealing temperature. Annealing at higher temperature may lead to a decrease in the concentration of structural defects in the crystal, thereby decreasing the defect-related emission more pronounced. However, the exact chemical origin of the individual defect emissions requires further study. It has been suggested that zinc vacancies were the source of green luminescence appeared at $2.4-2.6 \mathrm{eV}[50,51]$, but also surface defects and oxygen vacancies are under discussion as the source of green emission in $\mathrm{ZnO}[52,53]$. However, yellow emission has been attributed to the presence of OH-groups [54]. Since the broad emission in the yelloworange spectrum at $\sim 600 \mathrm{~nm}$ is minimized after annealing at $250^{\circ} \mathrm{C}$, it likely originates from the presence of $\mathrm{OH}$-groups whose desorption temperature is at $\sim 150^{\circ} \mathrm{C}$ [55]. 


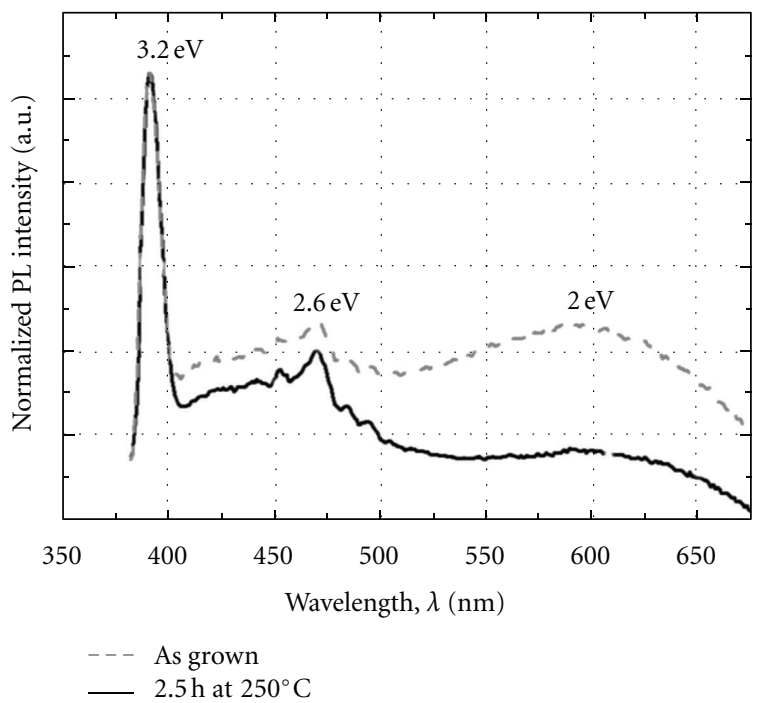

Figure 13: PL spectra of as grown ZnO NRAs (grey dashed) and after annealing at $250^{\circ} \mathrm{C}$ for $2.5 \mathrm{~h}$ (black solid). The PL spectra were recorded with an excitation wavelength of $325 \mathrm{~nm}$.

\section{Conclusion}

In summary, AZO substrates with different thicknesses have been used as TOEs for ECD in a self-seeding aqueous solution route to grow vertically aligned and single crystalline $\mathrm{ZnO}$ NRAs with wurtzite hexagonal phase. The deposition is carried out under mild and low-cost conditions without the use of any catalyst, surfactant, or seed mediator at temperatures between $60^{\circ} \mathrm{C}$ and $85^{\circ} \mathrm{C}$.

We found that the AZO substrate not only defines the density and orientation of the NRs, but also controls their diameter and vertical growth progression to a significant extent. Reason for this behaviour may be found in the grain size as well as the sheet resistance of the TOE. In this context, various AZO film thicknesses have been used to generate siteselective electrodeposition of parallel and closely spaced $\mathrm{ZnO}$ NRAs with tailored diameters.

The structural analysis shows that the realization of large aspect ratio $\mathrm{ZnO} \mathrm{NR}$ morphologies with good crystal quality is highly depending on the preparation conditions, a priori, on the temperature. The formation of high quality $\mathrm{ZnO}$ NRAs with large surface-to-volume ratio, on the other hand, is mainly dependent on the well-balanced ratio of zinc ions to hydroxide ions. With the reactant concentrations applied herein, this optimized growth condition is achieved at a bath temperature of $75^{\circ} \mathrm{C}$. It is also demonstrated that selforganization of fast-growing crystallographic planes of the inherent wurtzite crystal structure of $\mathrm{ZnO}$ is significantly promoted at elevated deposition temperatures, so that aspect ratios may be tailored in a range of two orders of magnitude by simply choosing a different AZO film thickness and consequently a changed grain size.

Room-temperature PL spectra showed strong UV emission and an improved UV-to-visible emission ratio, a clear indication for high optical quality $\mathrm{ZnO} \mathrm{NR}$ arrays. The $\mathrm{PL}$ emission characteristics of $\mathrm{ZnO}$ NRAs reveal significant sensitivity to the ECD synthesis temperature, thus the conditions they were prepared at.

The low-cost strategy, simple solution processing, fine quality, high reproducibility, and straightforward one-step synthesis in the herein presented work make the demonstrated ECD route on AZO TOEs attractive and considerable for large-scale production.

In the future, the presented ECD route is expected to extend further to the growth of multilayered and hierarchically structured thin-film materials by means of aqueous solution processing, since the controlled deposition of nanostructures of almost any metal oxide can be realized by selecting suitable reaction conditions.

\section{Acknowledgment}

The authors acknowledge financial support from the Austrian "Klima und Energie Fonds" project SANCELL.

\section{References}

[1] D. C. Look, "Recent advances in ZnO materials and devices," Materials Science and Engineering B, vol. 80, no. 1-3, pp. 383387, 2001.

[2] D. G. Thomas, "The exciton spectrum of zinc oxide," Journal of Physics and Chemistry of Solids, vol. 15, no. 1-2, pp. 86-96, 1960.

[3] Z. Q. Xu, H. Deng, Y. Li, Q. H. Guo, and Y. R. Li, "Characteristics of Al-doped c-axis orientation $\mathrm{ZnO}$ thin films prepared by the sol-gel method," Materials Research Bulletin, vol. 41, no. 2, pp. 354-358, 2006.

[4] W. Tang and D. C. Cameron, "Aluminum-doped zinc oxide transparent conductors deposited by the sol-gel process," Thin Solid Films, vol. 238, no. 1, pp. 83-87, 1994.

[5] O. Bamiduro, H. Mustafa, R. Mundle, R. B. Konda, and A. K. Pradhan, "Metal-like conductivity in transparent Al: $\mathrm{ZnO}$ films," Applied Physics Letters, vol. 90, no. 25, Article ID 252108, 2007.

[6] P. Kadam, C. Agashe, and S. Mahamuni, "Al-doped $\mathrm{ZnO}$ nanocrystals," Journal of Applied Physics, vol. 104, no. 10, Article ID 103501, 4 pages, 2008.

[7] K.-Y. Wu, C.-C. Wang, and D.-H. Chen, "Preparation and conductivity enhancement of Al-doped zinc oxide thin films containing trace Ag nanoparticles by the sol-gel process," Nanotechnology, vol. 18, no. 30, Article ID 305604, 2007.

[8] B.-Y. Oh, M.-C. Jeong, T.-H. Moon et al., "Transparent conductive Al-doped $\mathrm{ZnO}$ films for liquid crystal displays," Journal of Applied Physics, vol. 99, no. 12, Article ID 124505, 2006.

[9] P. F. Carcia, R. S. McLean, and M. H. Reilly, "Highperformance $\mathrm{ZnO}$ thin-film transistors on gate dielectrics grown by atomic layer deposition," Applied Physics Letters, vol. 88, no. 12, Article ID 123509, 2006.

[10] A. Tsukazaki, M. Kubota, A. Ohtomo et al., "Blue lightemitting diode based on $\mathrm{ZnO}$," Japanese Journal of Applied Physics, Part 2, vol. 44, no. 20-23, pp. L643-L645, 2005.

[11] R. H. Friend, R. W. Gymer, A. B. Holmes et al., "Electroluminescence in conjugated polymers," Nature, vol. 397, no. 6715, pp. 121-128, 1999.

[12] S. Tasch, E. J. W. List, O. Ekström et al., "Efficient white light-emitting diodes realized with new processable blends of conjugated polymers," Applied Physics Letters, vol. 71, no. 20, pp. 2883-2885, 1997. 
[13] M. H. Huang, S. Mao, H. Feick et al., "Room-temperature ultraviolet nanowire nanolasers," Science, vol. 292, no. 5523, pp. 1897-1899, 2001.

[14] M. Bender, E. Gagaoudakis, E. Douloufakis et al., "Production and characterization of zinc oxide thin films for room temperature ozone sensing," Thin Solid Films, vol. 418, no. 1, pp. 45-50, 2002.

[15] F. Patolsky, B. P. Timko, G. Zheng, and C. M. Lieber, "Nanowire-based nanoelectronic devices in the life sciences," MRS Bulletin, vol. 32, no. 2, pp. 142-149, 2007.

[16] Y. Qin, X. Wang, and Z. L. Wang, "Microfibre-nanowire hybrid structure for energy scavenging," Nature, vol. 451, no. 7180, pp. 809-813, 2008.

[17] Z. L. Wang and J. Song, "Piezoelectric nanogenerators based on zinc oxide nanowire arrays," Science, vol. 312, no. 5771, pp. 243-246, 2006.

[18] M. Law, L. E. Greene, J. C. Johnson, R. Saykally, and P. Yang, "Nanowire dye-sensitized solar cells," Nature Materials, vol. 4, no. 6, pp. 455-459, 2005.

[19] L. Vayssieres, K. Keis, S. E. Lindquist, and A. Hagfeld, "Purpose-built anisotropic metal oxide material: 3d highly oriented microrod array," The Journal of Physical Chemistry B, vol. 105, no. 17, pp. 3350-3352, 2001.

[20] C. Pacholski, A. Kornowski, and H. Weller, "Self-assembly of $\mathrm{ZnO}$ : from nanodots to nanorods," Angewandte Chemie, vol. 41, no. 7, pp. 1188-1191, 2002.

[21] X. Wang, J. Song, and Z. L. Wang, "Nanowire and nanobelt arrays of zinc oxide from synthesis to properties and to novel devices," Journal of Materials Chemistry, vol. 17, no. 8, pp. 711720, 2007.

[22] J. H. Burroughes, D. D. C. Bradley, A. R. Brown et al., "Lightemitting diodes based on conjugated polymers," Nature, vol. 347, no. 6293, pp. 539-541, 1990.

[23] C. W. Tang, "Two-layer organic photovoltaic cell," Applied Physics Letters, vol. 48, no. 2, pp. 183-185, 1986.

[24] M. Izaki and T. Omi, "Transparent zinc oxide films prepared by electrochemical reaction," Applied Physics Letters, vol. 68, no. 17 , pp. 2439-2440, 1996.

[25] S. Peulon and D. Lincot, "Cathodic electrodeposition from aqueous solution of dense or open-structured zinc oxide films," Advanced Materials, vol. 8, no. 2, pp. 166-170, 1996.

[26] E. M. Wong, J. E. Bonevich, and P. C. Searson, "Growth kinetics of nanocrystalline $\mathrm{ZnO}$ particles from colloidal suspensions," Journal of Physical Chemistry B, vol. 102, no. 40, pp. 7770-7775, 1998.

[27] X. Bubnova, A. Peić, T. Dimopoulos et al., "Electrochemical growth and characterization of zno nanorods on ito substrates, for solar cell applications," in Proceedings of the 26th European Photovoltaic Solar Energy Conference and Exhibition, pp. 483-486, 2011.

[28] T. Dimopoulos, G. Z. Radnoczi, B. Pécz, and H. Brückl, "Characterization of $\mathrm{ZnO}: \mathrm{Al} / \mathrm{Au} / \mathrm{ZnO}: \mathrm{Al}$ trilayers for high performance transparent conducting electrodes," Thin Solid Films, vol. 519, no. 4, pp. 1470-1474, 2010.

[29] T. Pauporté and D. Lincot, "Electrodeposition of semiconductors for optoelectronic devices: results on zinc oxide," Electrochimica Acta, vol. 45, no. 20, pp. 3345-3353, 2000.

[30] S. Peulon and D. Lincot, "Mechanistic study of cathodic electrodeposition of zinc oxide and zinc hydroxychloride films from oxygenated aqueous zinc chloride solutions," Journal of the Electrochemical Society, vol. 145, no. 3, pp. 864-874, 1998.

[31] M. Izaki and T. Omi, "Electrolyte optimization for cathodic growth of zinc oxide films," Journal of the Electrochemical Society, vol. 143, no. 3, pp. L53-L55, 1996.
[32] T. Yoshida, M. Tochimoto, D. Schlettwein, D. Wohrle, T. Sugiura, and H. Minoura, "Self-assembly of zinc oxide thin films modified with tetrasulfonated metallophthalocyanines by one-step electrodeposition," Chemistry of Materials, vol. 11, no. 10, pp. 2657-2667, 1999.

[33] M. Izaki and J. Katayama, "Characterization of boronincorporated zinc oxide film chemically prepared from an aqueous solution," Journal of the Electrochemical Society, vol. 147, no. 1, pp. 210-213, 2000.

[34] K. Govender, D. S. Boyle, P. B. Kenway, and P. O’Brien, "Understanding the factors that govern the deposition and morphology of thin films of $\mathrm{ZnO}$ from aqueous solution?" Journal of Materials Chemistry, vol. 14, no. 16, pp. 2575-2591, 2004.

[35] R. B. Peterson, C. L. Fields, and B. A. Gregg, "Epitaxial chemical deposition of $\mathrm{ZnO}$ nanocolumns from $\mathrm{NaOH}$ solutions," Langmuir, vol. 20, no. 12, pp. 5114-5118, 2004.

[36] J. Xie, H. Deng, Z. Q. Xu, Y. Li, and J. Huang, "Growth of ZnO photonic crystals by self-assembly," Journal of Crystal Growth, vol. 292, no. 2, pp. 227-229, 2006.

[37] T. Pauporté, Lecture Notes in Nanoscale Science and Technology, Springer, New York, NY, USA, 2009.

[38] L. Vayssieres, "Growth of arrayed nanorods and nanowires of $\mathrm{ZnO}$ from aqueous solutions," Advanced Materials, vol. 15, no. 5, pp. 464-466, 2003.

[39] Y. Sun, N. George Ndifor-Angwafor, D. Jason Riley, and M. N. R. Ashfold, "Synthesis and photoluminescence of ultrathin $\mathrm{ZnO}$ nanowire/nanotube arrays formed by hydrothermal growth," Chemical Physics Letters, vol. 431, no. 4-6, pp. 352357, 2006.

[40] I. Shalish, H. Temkin, and V. Narayanamurti, "Size-dependent surface luminescence in $\mathrm{ZnO}$ nanowires," Physical Review B, vol. 69, no. 24, Article ID 245401, pp. 1-245401, 2004.

[41] A. Goux, T. Pauporté, J. Chivot, and D. Lincot, "Temperature effects on $\mathrm{ZnO}$ electrodeposition," Electrochimica Acta, vol. 50, no. 11, pp. 2239-2248, 2005.

[42] D. Li, Y. H. Leung, A. B. Djurišić et al., "Different origins of visible luminescence in $\mathrm{ZnO}$ nanostructures fabricated by the chemical and evaporation methods," vol. 85, no. 9, pp. 16011603, 2004.

[43] M. H. Huang, Y. Wu, H. Feick, N. Tran, E. Weber, and P. Yang, "Catalytic growth of zinc oxide nanowires by vapor transport," Advanced Materials, vol. 13, no. 2, pp. 113-116, 2001.

[44] F. Xu, Y. Lu, Y. Xie, and Y. Liu, "Large-scale electrodeposition of $\mathrm{ZnO}$ thin films with novel petal-like architectures," Vacuum, vol. 83, no. 2, pp. 360-365, 2008.

[45] B. Xue, Y. Liang, L. Donglai et al., "Electrodeposition from $\mathrm{ZnO}$ nano-rods to nano-sheets with only zinc nitrate electrolyte and its photoluminescence," Applied Surface Science, vol. 257, no. 24, pp. 10317-10321, 2011.

[46] J.-Y. Chang, T. G. Kim, and Y.-M. Sung, "Synergistic effects of SPR and FRET on the photoluminescence of $\mathrm{ZnO}$ nanorod heterostructures," Nanotechnology, vol. 22, no. 42, Article ID 425708, 2011.

[47] S. C. Lyu, Y. Zhang, H. Ruh et al., "Low temperature growth and photoluminescence of well-aligned zinc oxide nanowires," Chemical Physics Letters, vol. 363, no. 1-2, pp. 134-138, 2002.

[48] L. E. Greene, M. Law, J. Goldberger et al., "Low-temperature wafer-scale production of $\mathrm{ZnO}$ nanowire arrays," Angewandte Chemie, vol. 42, no. 26, pp. 3031-3034, 2003.

[49] A. B. Djurišić, Y. H. Leung, K. H. Tam et al., "Green, yellow, and orange defect emission from $\mathrm{ZnO}$ nanostructures: influence of excitation wavelength," Applied Physics Letters, vol. 88, no. 10, Article ID 103107, 2006. 
[50] A. Sosin and H. M. Simpson, "Dislocation-defect dragging in electron-irradiated copper over the temperature range 4.2$350^{\circ}$ K," Journal of Applied Physics, vol. 49, no. 1, pp. 188-196, 1978.

[51] D. C. Reynolds, D. C. Look, B. Jogai, and H. Morkoç, "Similarities in the bandedge and deep-centre photoluminescence mechanisms of $\mathrm{ZnO}$ and GaN," Solid State Communications, vol. 101, no. 9, pp. 643-646, 1997.

[52] F. A. Kröger and H. J. Vink, "The origin of the fluorescence in self-activated $\mathrm{ZnS}$, CdS, and $\mathrm{ZnO}$," The Journal of Chemical Physics, vol. 22, no. 2, pp. 250-252, 1954.

[53] P. H. Kasai, "Electron spin resonance studies of donors and acceptors in ZnO," Physical Review, vol. 130, no. 3, pp. 989 995, 1963.

[54] N. S. Norberg and D. R. Gamelin, "Influence of surface modification on the luminescence of colloidal $\mathrm{ZnO}$ nanocrystals," Journal of Physical Chemistry B, vol. 109, no. 44, pp. 20810 20816, 2005.

[55] R. Xie, T. Sekiguchi, T. Ishigaki et al., "Enhancement and patterning of ultraviolet emission in $\mathrm{ZnO}$ with an electron beam," Applied Physics Letters, vol. 88, no. 13, Article ID 134103, 2006. 

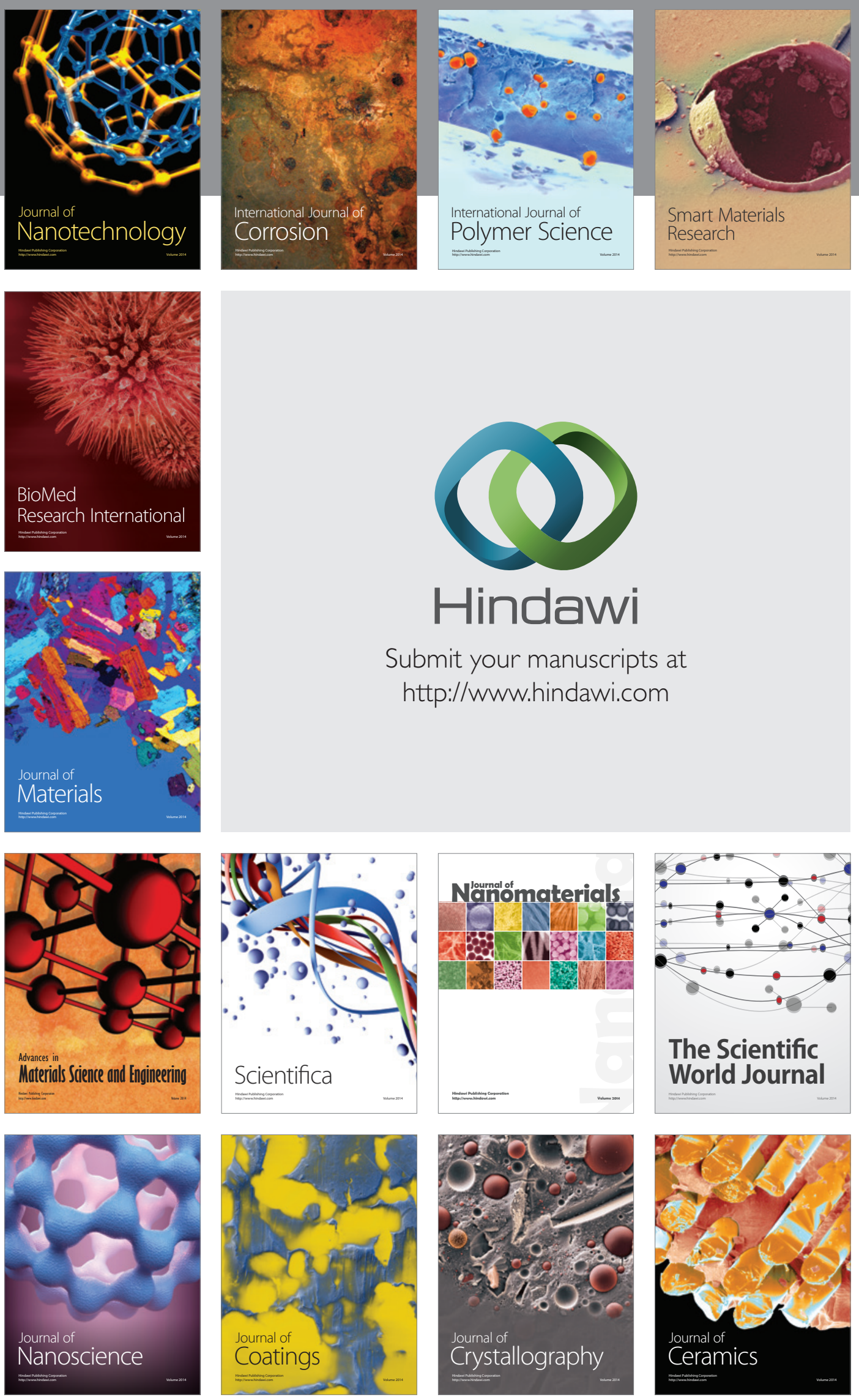

The Scientific World Journal

Submit your manuscripts at

http://www.hindawi.com

\section{World Journal}

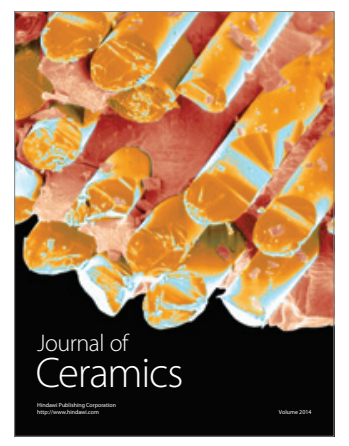

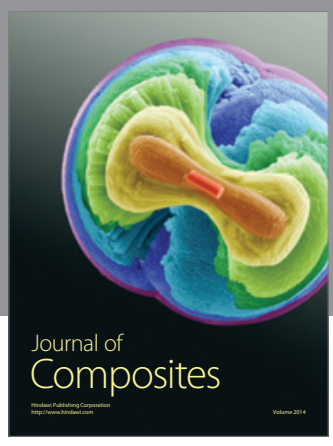
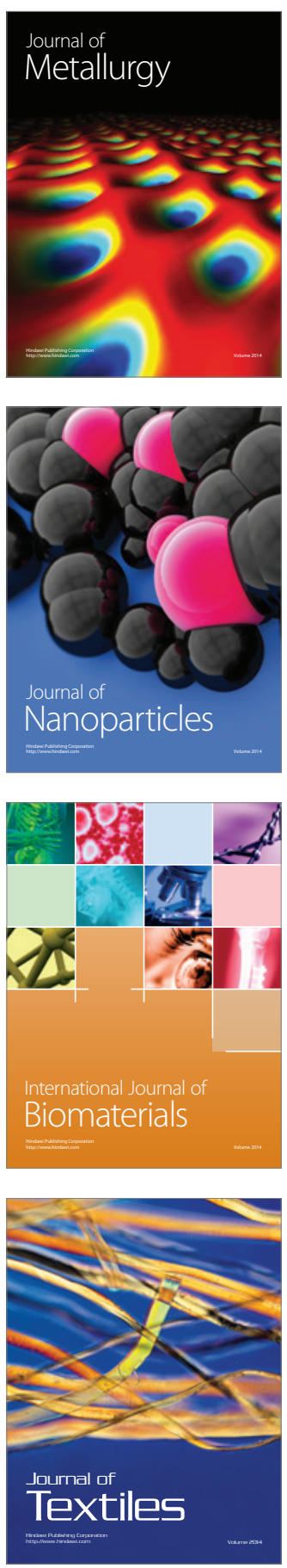